\title{
Effect of platelet-rich plasma and microfracture reparative technique combined in chondral lesions treatment
}

\author{
Pietro Zedde, ${ }^{1}$ Sebastiano Cudoni, ${ }^{2}$ Pietro Lisai, ${ }^{1}$ Mario Fadda, ${ }^{1}$ Andrea Fabio Manunta ${ }^{1}$ \\ 'Orthopedic and Traumatology Unit, Department of Biomedical Science, Sassari University Hospital, \\ Sassari; ${ }^{2}$ Orthopedic and Traumatology Unit, Nuoro Hospital, Nuoro, Italy
}

\begin{abstract}
The microfracture surgery introduced by Stedman despite limitations still represents the most common procedure to repair chondral defects. In recent years other regeneration techniques, such as the implantation of platelet-rich plasma (PRP), have been adopted in combination to boost and promote successful outcomes. This study aimed at evaluating clinical and functional results in 60 patients affected by chondral lesions and treated only using the microfracture procedure or in combination with intra-articular PRP infiltration. Patients were sub-divided in 2 groups: 30 were treated with microfracture reparative technique and the remaining 30 microfractures were treated with 3 platelet-rich plasma intra-articular injections. All patients were postoperatively evaluated based on the visual along scale, International Knee Documentation Committee, subjective knee function, and Lysholm knee scoring scale. The evaluation results for each follow-up showed an improvement of all evaluation scores compared to the preoperative phase and a variable and progressive deterioration registered at 24, 36 and 48-month follow-up visits, more pronounced in patients treated with microfracture alone. Instead, more successful outcomes in terms of pain symptomatology and functional recovery were reported during all follow-up visits and based on all scoring scales for the 30 patients treated with a combination of both techniques. The combination of the microfracture reparative technique and the platelet-rich plasma implantation favoured a faster resolution of pain symptomatology and a quicker functional recovery with favourable results maintained over time.
\end{abstract}

Correspondence: Pietro Zedde, Orthopedic and Traumatology Unit, Department of Biomedical Science, Sassari University Hospital, viale San Pietro 43, 07100 Sassari, Italy.

Tel. +39.079.228356.

E-mail: pietrozedde@tiscali.it

Key words: Cartilage; Injury; Microfracture; Regeneration; Platelet-rich plasma.

Received for publication: 15 April 2015.

Revision received: 26 August 2015.

Accepted for publication: 21 October 2015.

CC Copyright P. Zedde et al., 2015

Licensee PAGEPress, Italy

Journal of Biological Research 2015; 88:5229

This article is distributed under the terms of the Creative Commons Attribution Noncommercial License (by-nc 3.0) which permits any noncommercial use, distribution, and reproduction in any medium, provided the original author(s) and source are credited.

\section{Introduction}

Fifty years after the report of the first reparative procedure and 25 years after the first autologus chondrocyte transplantation, chondral lesions treatment still represents a great challenge for othopedic surgeons ${ }^{1}$ and for this reason it is currently an issue of considerable interest. $^{2}$ Approximately 900,000 individuals with cartilage lesions are treated yearly in US by an orthopedic surgeon. ${ }^{3}$ A study conducted by Curl and colleagues on 31,516 patients who underwent knee arthroscopy reported the presence of chondral lesions in $63 \%$ of cases. ${ }^{4}$ Currently, the procedures can be divided into two big categories: reparation techniques and regenerative techniques. The rationale for reparation interventions is based on direct stimulation of subchondral bone mesenchymal cells, which are able to induce coagulation resulting in the reparation of the chondral defect. Instead, regenerative interventions include chondral and osteochondral transplantation as well as recent advancements in tissue engineering aiming at obtaining a hyaline-like cartilage tissue and restoring the joint surface both from the biological and the biomechanical point of view.

Regardless of the type of approach selected, the chondral lesions treatment aims at achieving the main goals of join cartilage restoration: the return to normal daily and sport activities, and arthrosis prevention. ${ }^{5}$

In such a setting characterized by the continuous development of novel techniques and materials, microfracture performed using the Stedman procedure still represents the most adopted method to repair chondral defects. ${ }^{6-9}$ The biological rationale of this reparative technique is based on direct stimulation of the subchondral bone mesenchymal cells having a high chondrogenic differentiation potential. ${ }^{10-}$ ${ }^{13}$ Advantages of this procedure include the limited invasivity, reduced cost, the fact that it is relatively easy to perform, and a good outcome, especially in young patients with limited defects. ${ }^{12,13}$

The quality and characteristics of the newly formed fibrocartilage tissue rich in type I collagen with limited biomechanical properties and a tendency toward degeneration have been widely discussed in the literature and are still under debate. ${ }^{14-16}$ Factors associated with the best results seem to be the defect reduced size, ${ }^{17}$ the low degree of the lesion, the unifocality, ${ }^{18}$ and the time lapse between the traumatic event and the treatment. ${ }^{19}$

In order to boost and promote results achieved by using the microfracture procedure to treat chondral defects, regenerative techniques have been often associated in recent years to reparation techniques, such as the use of the platelet-rich plasma (PRP) among others. Numerous studies in literature report that growth factors contained in PRP promote chondrocytes synthesis through gene expression regulation, proteoglycan production and type II collagen deposition. ${ }^{20}$

The purpose of this study was to evaluate the clinical and functional results in 60 patients with chondral lesions treated only by using microfracture or combining this procedure with PRP infiltration. 


\section{Materials and Methods}

Once signed informed consent was obtained, sixty patients treated between 2010 and 2013 were enrolled into the study, diagnosed with chondral lesions grade III to IV on the medial femoral condyle and size of less than $2 \mathrm{~cm}$, according to the International Cartilage Repair Society (ICRS) scoring. All patients aged 25-45 years had a body mass index 30, good knees stability, no meniscal lesions and no patellar malalignment or maltracking. Patients with rheumatoid arthritis, metabolic disorders, immunodeficiency, hepatitis B or C and HIV were excluded from the study as well as patients whose affected knee previously underwent surgical treatment.

Patients were randomly divided into two groups. Thirty patients were treated by using the Stedman's microfracture procedure (Group A) and the remaining 30 combining Stedman's procedure with three PRP intra-articular injections weekly for a three-week period (Group B). The surgical procedure was performed with patient in supine position, local anaesthesia and a tourniquet just above the knee. A joint exploration was carried out through standard arthroscopic portals in order to identify the chondral lesion and score it based on the ICRS arthroscopic system, and to evaluate the presence of eventual lesions affecting meniscus or ligaments.

Treatment of the defect included also a preliminary lesion debridement aimed at obtaining clear-cut hedges and stable hedges and removing the calcified cartilage by using a curette to avoid going too deep into the subchondral bone; once the bottom of the lesion was prepared, 3-4 mm-deep perforations were performed using a specific conica awl with an approximately $4 \mathrm{~mm}$ bone bridge between perforations.

Furthermore, thirty of these patients were treated with PRP intraarticular infiltrations on the seventh, fourteenth and twenty-first day after surgery. Thirty $\mathrm{mL}$ of venous blood taken from the patients' ulnar vein were centrifuged for $15 \mathrm{~min}$ at $3200 \mathrm{rpm}$ (centrifugation speed $1327 \mathrm{~g}$ ). Venous blood centrifugation causes the separation of the different haematic components with different density gradients. The $3 \mathrm{~mL}$ PRP obtained were infiltrated into the knee previously treated by microfracture reparative surgery.

Both patients' groups, based on a standard rehabilitation protocol, avoided weight-bearing on the treated knee for 6 weeks after the arthroscopy, the use of continuous passive motion (CPM) since the first postoperative day and a gradual increase until the full recovery of joint excursion, alongside with closed kinetic chain exercises to increase stability and core-stability until return to normal day life activities in approximately 8 weeks.

All patients previously evaluated during the preoperative phase were reassessed with a 3, 6 and 12-month follow-up and through annual follow-up visits, based on the visual along scale (VAS), the international knee documentation committee (IKDC), the subjective knee function and the Lysholm Knee scoring scale to perform both a clinical and functional evaluation. The maximum length of follow-up was 48 months.

\section{Results}

The two treatment groups were homogeneous for gender, age, body mass index and follow-up (Table 1). Fifty-two patients accepted to take part to the final follow-up, 24 from Group A and 28 from Group B. The analysis of results showed that during all follow-up visits an improvement of all evaluation scores could be observed compared to the preoperative phase; moreover, during evaluations performed at 24,36 and 48 months it was observed a variable and progressive deterioration, more accentuated in patients treated with microfracture alone. Since 3 patients belonging to this group showed the same symptomatology reported during the preoperative period, the decision was taken to treat them at 2 or 3 years distance from the arthroscopy with three PRP infiltrations; a clinical and functional improvement was noted afterwards. Results more satisfactory were reported, both for what concerns pain symptomatology and functional recovery, in all 30 patients treated with reparative microfracture surgery in combination with PRP implantation during all follow-up visits and based on all the scoring systems. However, also for this group a decline of achieved results has been reported at 24,36 and 48 months even though scores reached by patients were still higher than those registered during the preoperative phase (Tables 2, 3 and 4). Complications have been observed in any patient.

\section{Discussion}

Several studies in literature report that growth factors contained in PRP promote chondrocytes synthesis through regulation of gene expression, proteoglycans production and type II collagen deposition. ${ }^{21,22}$

Table 1. Patients' groups characteristics.

\begin{tabular}{lccccc} 
Group & \multicolumn{2}{c}{ Gender } & Age (years) & BMI (kg/m²) & Follow-up (n) \\
A & 18 & 12 & $33.8 \pm 6.7$ & $25.3 \pm 0.3$ & $28.4 \pm 11.89$ \\
B & 16 & 14 & $32.6 \pm 6.06$ & $24.9 \pm 0.2$ & $28.1 \pm 10.7$ \\
\hline
\end{tabular}

BMI, body mass index.

Table 2. Visual along scale evaluation.

\begin{tabular}{lcccccc} 
Group & $\begin{array}{c}\text { Pre-0peratively } \\
\text { VAS }\end{array}$ & $\begin{array}{c}\text { VAS at } \\
\text { month } 12\end{array}$ & $\begin{array}{c}\text { VAS at } \\
\text { month } 16\end{array}$ & $\begin{array}{c}\text { VAS at } \\
\text { month } 24\end{array}$ & $\begin{array}{c}\text { VAS at } \\
\text { month } 36\end{array}$ & $\begin{array}{c}\text { VAS at } \\
\text { month } 48\end{array}$ \\
A & $5.44 \pm 0.85$ & $2.03 \pm 0.88$ & $2.62 \pm 1.21$ & $2.61 \pm 0.88$ & $2.9 \pm 0.75$ & $3.23 \pm 1.88$ \\
B & $5.13 \pm 0.77$ & $1.82 \pm 0.79$ & $2.1 \pm 0.88$ & $2.31 \pm 0.83$ & $2.61 \pm 0.77$ & $2.9 \pm 0.72$ \\
\hline
\end{tabular}


Table 3. International Knee Documentation Committee scoring system.

\begin{tabular}{ccccccc} 
Group & $\begin{array}{c}\text { Pre-0peratively } \\
\text { IKDC }\end{array}$ & $\begin{array}{c}\text { IKDC at } \\
\text { month } 12\end{array}$ & $\begin{array}{c}\text { IKDC at } \\
\text { month 16 }\end{array}$ & $\begin{array}{c}\text { IKDC at } \\
\text { month 24 }\end{array}$ & $\begin{array}{c}\text { IKDC at } \\
\text { month 36 }\end{array}$ & $\begin{array}{c}\text { IKDC at } \\
\text { month 48 }\end{array}$ \\
A & $37.63 \pm 10.57$ & $82.21 \pm 9.42$ & $65.32 \pm 8.71$ & $75.31 \pm 10.52$ & $59.21 \pm 7.22$ & $54.21 \pm 6.5$ \\
B & $35.46 \pm 6.55$ & $85.33 \pm 6.55$ & $69.31 \pm 7.42$ & $84.37 \pm 8.57$ & $79.01 \pm 6.21$ & $65.58 \pm 7.21$ \\
\hline
\end{tabular}

IKDC, International Knee Documentation Committee.

Table 4. Lysholm evaluation.

\begin{tabular}{lccccccc} 
Group & $\begin{array}{c}\text { Pre-0peratively } \\
\text { Lysholm }\end{array}$ & $\begin{array}{c}\text { Lysholm at } \\
\text { month } 12\end{array}$ & $\begin{array}{c}\text { Lysholm at } \\
\text { month 16 }\end{array}$ & $\begin{array}{c}\text { Lysholm at } \\
\text { month } 24\end{array}$ & $\begin{array}{c}\text { Lysholm at } \\
\text { month 36 }\end{array}$ & $\begin{array}{c}\text { Lysholm at } \\
\text { month } \mathbf{4 8}\end{array}$ \\
A & $35.90 \pm 8.96$ & $81.23 \pm 9.41$ & $64.66 \pm 14.57$ & $78.31 \pm 7.98$ & $62.15 \pm 9.24$ & $60.21 \pm 7.22$ \\
B & $37.76 \pm 10.09$ & $87.21 \pm 10.57$ & $67.00 \pm 14.64$ & $85.32 \pm 8.41$ & $72.31 \pm 10.09$ & $66.81 \pm 6.21$ \\
\hline
\end{tabular}

Platelet-rich plasma has a high concentration of platelets that once implanted release in the site important growth factors such as the platelet-derived growth factor, the transforming growth factor- $\beta$ (TGF$\beta$ ), the fibroblast growth factor, the insulin-like growth factor (IGF-1 and IGF-2) and the vascular endothelial growth factor. Among these, the TGF$\beta$ seems to play a key-role to support and enhance other growth factors. ${ }^{23}$

Growth factors play an important role in maintaining the cartilage tissue and joint structures homeostasis as a whole ${ }^{24-26}$ and thanks to their interaction they give a contribution to the increasing of chondral phenotype cells expression and proliferation, they stimulate the mesenchymal stem cells differentiation in a chondrogenic sense, they promote the matrix deposition and slow down the matrix catabolism, and they reduce the suppressive effect exerted by the inflammatory mediators on the proteoglycans synthesis. The biological rationale of PRP implementation in degenerative joint pathology is to obtain a local concentration of growth factors capable of promoting the maintenance of joint homeostasis $^{27,28}$ and preventing the joint damage. ${ }^{29}$ Several in vivo studies based on animal and clinical models showed the efficacy of PRP both for chondral lesions and in the early degenerative joint pathology.

In the recent past the use of platelet concentration has been increasingly adopted. Sanchez and colleagues published a comparative study conducted on 60 patients affected by knee arthrosis: 30 were treated by PRP and 30 by hyaluronic acid (HA) infiltrations. The analysis of results showed that the group treated with growth factors presented higher results, with a more effective control of pain and a more satisfactory recovery of joint excursion. ${ }^{28}$ In addition, the Saegusa group reported a good pain symptomatology management and an improvement of joint functionality in a cohort of 261 patients treated with PRP implantation and evaluated at a 6-month follow-up. ${ }^{30,31}$ Besides, Kon and colleagues reported clinical and functional results of patients with chondral lesions and first-stage arthrosis treated with infiltration cycles performed on a weekly basis. Results show a significant improvement at 6 and 12-month follow-up. ${ }^{32}$

TGF- $\beta 1$, also known as the cartilage-inducing factor and the differentiation inhibitor factor, is a protein formed by two monomers of 120 amino acids amino acids joined by a disulphide bond with a cystine knot structure. Among the three TGF- $\beta$ isoforms, the $\beta 1$ is the most abundant and it is secreted by almost all cells. It is a multifunctional cytokine that regulates proliferation, growth, differentiation, migration and synthesis of the extracellular matrix. Furthermore, it is involved into embryogenesis, in tissue remodelling and wound repair. ${ }^{33}$ It emerged from different studies that TGF- $\beta$ induces chondrogenesis via protein kinases such as p38, protein kinase A, protein kinase $\mathrm{C}$ and Jun kinase; this has been demonstrated by the increase of chondrogenic markers expression such as Sox9 and collagen II. Among others, it induces the Wnt expression which up-regulates the $\mathrm{N}$-cadherin expression, that is a crucial molecule during the first stages of cartilage formation to create the adhesion complex. There are several advantages deriving from the use of PRP. In the first place it is an easy to perform procedure, fast, inexpensive and one-step which acts on cells in the defect site. Unfortunately there is not an agreement in the literature on the quality of the tissue newly formed after the two-techniques combination. For instance, Milano et al. in a study performed on an ovine model combining the two techniques reported the absence of newly formed hyaline cartilage based on histological evaluations. ${ }^{34}$ The most obvious limitation of the study is not to performed the evaluation MRI after treatment.

\section{Conclusions}

Chondral defects treatment can now rely on different regenerative techniques, which aim at promoting the restoration of the joint surface based on a biological and a biomechanical approach at the same time. An effective strategy to achieve this goal is represented by the combination of Stedman's surgery with PRP infiltrations; indeed PRP, thanks to the action exerted by several growth factors contained in platelets, may act as a great support both to rapidly resolve the inflammatory process and to promote chondral defects regeneration.

Unlike what was observed in treatments based on the microfracture procedure alone, the combination of the microfracture reparative technique with the PRP implantation enhances a faster resolution of pain symptomatology and a quicker functional recovery with a good maintenance of results achieved over the time. However, to better define the real effects of the two techniques combined together further welldesigned and randomized studies are warranted, including adequate biomechanical and histological evaluations of long-term results.

\section{References}

1. Shetty AA, Kim SJ, Nakamura N, et al. Techniques in cartilage repair surgery. Springer, Amsterdam, The Netherlands. 
2. Berruto M, Zedde P, Uboldi FM, et al. Il danno condrale nel calciatore. J Sport Traumatol 2013;30:127-33.

3. Browne JE, Branch TP. Surgical alternatives for treatment of articular cartilage lesions. J Am Acad Orthop Sur 2000;8:180-9.

4. Curl WW, Krome J, Gordon ES, et al. Cartilage injuries: a revew of 31516 knee arthroscopies. Arthroscopy 1997;13:456-60.

5. Pànics G, Hangody LR, Balò E, et al. Osteochondral autograft and mosaicplasty in the football athlete. Cartilage 2012;3:31-6.

6. Steadman JR, Miller BS, Karas SG, et al. The microfracture technique in the treatment of full-thickness chondral lesions of the knee in National Soccer League players. J Knee Surg 2003;16:83-6.

7. Brophy RH, Rodeo SA, Barnes RP, et al. Knee articular cartilage injuries in the National Football League: epidemiology and treatment approach by team physicians. J Knee Surg 2009;22:331-8.

8. Riyami M, Rolf C. Evaluation of microfracture of traumatic chondral injuries to the knee in professional football and rugby players. J Orthop Surg Res 2009;4:13-22.

9. Mithoefer K, Williams RJ, Warren RF, et al. High-impact athletics after knee articular cartilage repair: a prospective evaluation of the microfracture technique. Am J Sport Med 2006;34:1413-8.

10. Khan WS, Johnson DS, Hardingham TE, et al. The potential of stem cells in the treatment of knee cartilage defects. Knee 2010;17:36974 .

11. Shapiro F, Koide S, Glimcher MJ, et al. Cell origin and differentiation in the repair of full-thickness defects of articular cartilage. $J$ Bone Joint Surg Am 1993;75:532-53.

12. Mithoefer K, Williams RJ, Warren RF, et al. The microfracture technique for the treatment of articular cartilage lesions in the knee: a prospective cohort study. J Bone Joint Surg Am 2005;87:1911-20.

13. Mithoefer K, Williams RJ, Warren RF, et al. Chondral resurfacing of articular cartilage defects in the knee with the microfracture technique. J Bone Joint Surg Am 2006;88:294-304.

14. Saris DB, Vanlauwe J, Victor J, et al. Characterized chondrocyte implantation results in better structural repair when treating symptomatic cartilage defects of the knee in a randomized controlled trial versus microfracture. Am J Sport Med 2008;36:235-46.

15. Saris DB, Vanlauwe J, Victor J, et al. Treatment of symptomatic cartilage defects of the knee: characterized chondrocyte implantation results in better clinical outcome at 36 months in a randomized trial compared to microfracture. Am J Sport Med 2009;37(Suppl.1):10-9.

16. Vanlauwe J, Saris DB, Victor J, et al. Five-year outcome of characterized chondrocyte implantation versus microfracture for symptomatic cartilage defects of the knee: early treatment matters. Am J Sport Med 2011;39:2566-74.

17. Bae DK, Song SJ, Yoon KH, et al. Survival analysis of microfracture in the osteoarthritic knee-minimum 10-year follow-up. Arthroscopy 2013;29:244-50.

18. Solheim E, Oyen J, Hegna J, et al. Microfracture treatment of single or multiple articular cartilage defects of the knee: a 5-year median follow-up of 110 patients. Knee Surg Sport Tr A 2010;18:504-8.

19. Mithoefer K, McAdams T, Williams RJ, et al. Clinical efficacy of the microfracture technique for articular cartilage repair in the knee: an evidence-based systematic analysis. Am J Sport Med 2009;37:2053-63.

20. Smith NA, Murawski CD, Fortier LA, et al. Platelet-rich plasma in the pathologic processes of cartilage: review of basic science evidence. Arthroscopy 2013;29:1399-409.

21. Akeda K, An HS, Okuma M, et al. Platelet-rich plasma stimulates porcine articular chondrocyte proliferation and matrix biosynthesis. Osteoarthr Cartilage 2006;14:1272-80.

22. Wu W, Chen F, Liu Y, et al. Autologous injectable tissue-engineered cartilage by using platelet-rich plasma: experimental study in a rabbit model. J Oral Maxil Surg 2007;65:1951-7.

23. Hammond JW, Hinton RY, Curl LA, et al. Use of autologous plateletrich plasma to treat muscle strain injuries. Am J Sport Med 2009;37:1135-42.

24. Frazer A, Bunning RA, Thavarajah M, et al. Studies on type II collagen and aggrecan production in human articular chondrocytes in vitro and effects of transforming growth factor-beta and interleukin-1beta. Osteoarthr Cartilage 1994;2:235-45.

25. Pujol JP, Chadjichristos C, Legendre F, et al. Interleukin-1 and transforming growth factor-beta 1 as crucial factors in osteorthritic cartilage metabolism. Connect Tissue Res 2008;49:293-7.

26. Schmidt MB, Chen EH, Lynch SE. A review of the effects of insulinlike growth factor and platelet derived growth factor on in vivo cartilage healing and repair. Osteoarthr Cartilage 2006;14:403-12.

27. Anitua E, Andia I, Ardanza B, et al. Autologous platelets as a source of proteins for healing and tissue regeneretion. Thromb Haemostasis 2004;91:4-15.

28. Andad SX, Viles-Gonzalez JF, Badimon JJ, et al. Membrane-associated $\mathrm{CD} 40 \mathrm{~L}$ and $\mathrm{SCD} 40 \mathrm{~L}$ in atherothrombotic disease. Throm Haemostasis 2003;90:377-84.

29. Saito M, Takahashi KA, Arai Y, et al. Intraarticular administration of platelet-rich plasma with biodegradable gelatin hydrogel microspheres prevents osteoarthritis progression in the rabbit knee. Clin Exp Rheumatol 2009;27:201-7.

30. Sànchez M, Anitua E, Azofra J, et al. Intra-articular injection of an autolgous preparation rich in growth factors for the treatment of knee 0A: a retrospective cohort study. Clin Exp Rheumatol 2008;26:910-3.

31. Wang-Saegusa A, Cugat R, Ares 0, et al. Infiltration of plasma rich in growth factors for osteoarthritis of the knee short-term effects on function and quality of life. Arch Orthop Trauma Surg 2011;131:311-7.

32. Kon E, Buda R, Filardo G, et al. Platelet-rich plasma: intra-articular knee injections produced favorable results on degenerative cartilage lesions. Knee Surg Sport Tr A 2010;18:472-9.

33. Sporn MB, Roberts AB. The transforming growth factor-betas: past, present, and future. Ann NY Acad Sci 1990;593:1-6.

34. Milano G, Sanna Passino E, Deriu L, et al. The effect of platelet rich plasma combined with microfractures on the treatment of condrale defects: an experimental study in a sheep model. Osteoarthr Cartilage 2010;18:971-80. 